\title{
Urban entropy vs sustainability: a new town planning perspective
}

\author{
R. Fistola \\ Department of Engineering, University of Sannio, Italy
}

\begin{abstract}
The city, interpreted as a complex dynamic system, is experiencing ungovernable levels of entropic growth related to locally-based human activities. Indeed, the main antagonist of urban sustainability is anthropogenic entropy. The general crisis is due to the production of entropy within single urban subsystems, which is transmitted, with a ripple effect, to all the others and to the entire city. Due to endogenous malfunctioning in its parts or in its structure, a subsystem can be viewed as an "entropic generator" and can trigger a chain of damage that can lead to the collapse of the entire urban system. The urban crisis can thus be linked to the entropy produced, especially within the human subsystem. In order to start appropriate processes that gear the structure of the urban system towards sustainability measures, it is first necessary to reduce urban entropy. New procedures are being developed to plan sustainable cities which, in a cyclical process, are also rooted in social capital. Entropy can be distinguished in directaction, expressed as soil use (how, where, for how long) and entropy-induced action which is carried out by the activities producing air, electromagnetic noise, water pollution. This paper, also starting from the studies developed by E. Tiezzi and the paper by F. Muller (presented at "Sustainable city 2010" in La Coruňa), seeks to identify the characteristics of anthropogenic entropy in order to propose the adoption of a new "urban ethic" which has to become one of the determinants of eco-town planning.
\end{abstract}

Keywords: sustainable city, complex system, systemic approach, entropy, ecotown planning. 


\section{City as a system}

The proposed reflection within these pages is based mainly on the adoption of a systemic paradigm for the interpretation of the structure, organization and evolution of the city. As stated in the paper presented at the 2010 Sustainable City Conference of La Coruña [1], in order to address the question of urban evolution and transformation it is necessary to apply a paradigm, a model that allows the components to be specified, the process to be analyzed and behaviour schematized.. The city can be intended as a dynamically complex system that evolves in space and time following trajectories that are hard to predict [2]. However, these very characteristics of complexity and dynamic evolution have represented the main critical factors for town planning, generally involved in drawing up forecasts - closed and static - of the future urban layout. It is thus necessary to draw up new theories of town planning that consider systemic evolution [3].

Eco-town planning seeks to satisfy this need with special attention to the development of sustainable measures. In the following pages the scientific basis of eco-town planning will be analyzed in depth. As stressed by some major contributions, the systemic approach allows the city to be viewed as a dynamically complex system, and complexity is the strategic factor ensuring system evolution [4]. One of the system's characteristics is that it allows one to think about a subdivision into component subsystems. Among the subsystems we may distinguish some that can be considered most important (or reference), and others, still referring to, which characterize the system with reference to a specific characteristic: the economic system, the transport system and so on.

In particular, we can identify five main urban subsystems [5] (Figure 1).

The physical subsystem, of material type, formed by the spaces and channels of interconnection among them; the functional subsystem, of abstract type, represented by the activities occurring in the urban space or running through the area; the psycho-perceptive system, of abstract type, represented by the image of the space lived in which each citizen has inside him/her; the geomorphological system, of material type, formed by the environmental substratum of the ecosystem, and for which the parts can be identified in defined territorial areas (continents, nations, hydrographical basins, macro regions, municipal areas, and so on) and the relationships in the infrastructure of physical connection among them (roads, railways, canals, energy networks and so on).

The anthropic/human system is represented by the "biocenotic" component of the city, the community that gives a sense to the space. The components of this system are represented by the human aggregations acting inside urban space: the actors and the relationships; interactions between groups and/or individuals that work for the development of the city. The geomorphological system and the anthropic/human one are to be considered as "generative" subsystems because they allow the generation of the urban system, without which the city would never exist.

The physical system and the functional system can be considered as "generated" systems which born from the presence or interaction of generative 


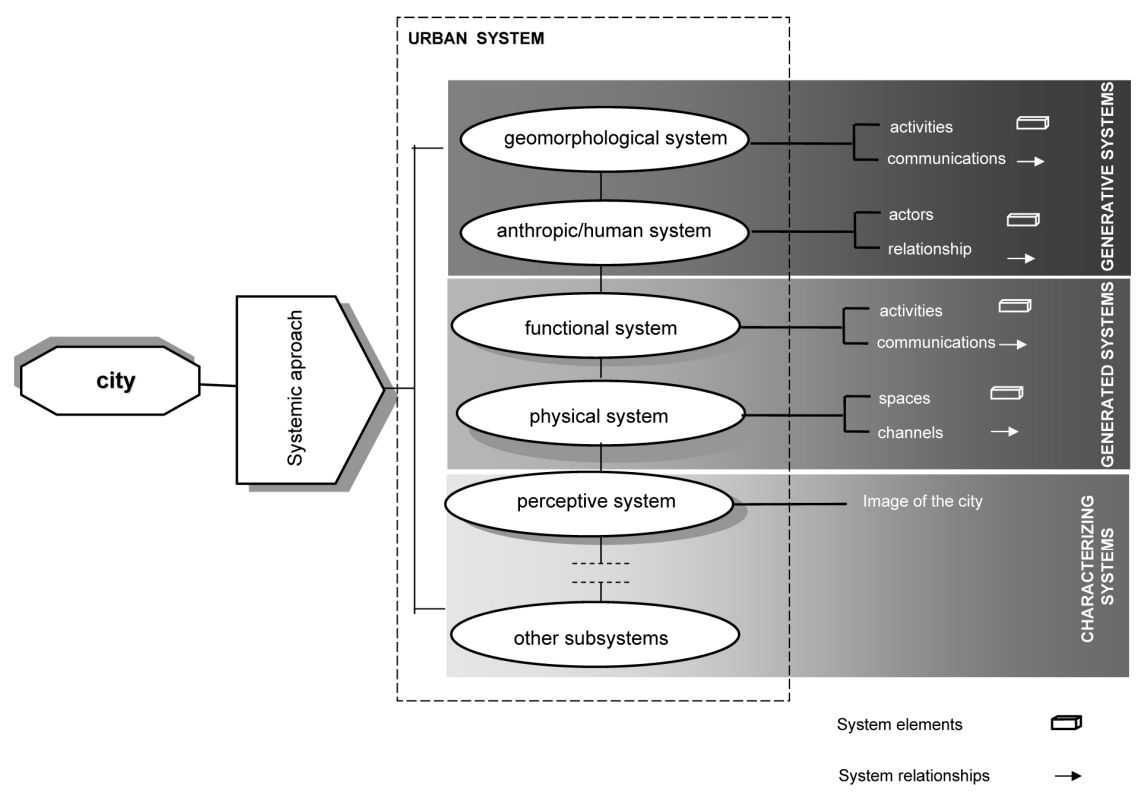

Figure 1: The urban system and the five sub-systems detected in the systemic approach.

systems. As stated above, in each system the elements forming the systemic architecture should be found: the parts and the relationships (the set of the system relationships is called "structure"). As regards the physical system the parts can be found in the built-up spaces of the city (buildings, squares, equipment, urban sites, and so on) and the relationships in the communication channels between the spaces that represent the "supporters" of the functional flows, which will be dealt with in the following pages, (roads, urban connectors, hydraulic infrastructure, energy and computer networks, and so on).

The functional system consists of the human activities, placed in the physical spaces, and of the relationships represented by the interconnection flows between the actions that form the transaction process characterizing the city.

The physical system and the functional one are systems deriving from the generative subsystems because produced by changes of the natural environment activities. Another generated basic system is the psycho-perceptive one constituted by the image of the city that each citizen forms within him/herself also by referring to his/her own cognitive and emotional heritage [6]. The perception of the urban system takes place thanks to the presence of a material space that contains the human and transactional activities of the city, but also with reference to events and activities taking place in specific sites. Such elements contribute to build the "memory of places", which is one of the most important elements in the evolution of urban systems and which eco-town planning suggests should be protected. 


\section{Entropy vs sustainability}

If the parts and relationships of urban subsystems were properly balanced, cities would exist in a sustainable dynamic state. Problems arise when one or more subsystems change their normal evolution trajectories and start a considerable production of entropy [7]. Entropy is the phenomenon to be detected and prevented in order to achieve urban sustainability. Referring to the systemic paradigm, in the light of the previous assumptions, the city can be approached as a dynamic and complex system (or dynamically complex). This system changes and develops in space and time, namely it moves diachronically and evolves "within itself". In other words the urban system changes, moment by moment, because of the changes in its parts and the relationships linking them.

In addition, still referring to systemic theory, it may be stated that the city is capable of starting self-regulation processes, theorized as "capability of adaptation, which means that the components (parts and relationships) organize and change, reacting also to external cues, according to endogenous processes.

To give an example linked to the mobility function, if inside a city some road segments were closed to traffic, there would be a general reorganization of mobility by changing the direction and intensity of flows. That reorganization makes an impact on the whole system due to the different composition of the flows. Similarly, a systemic change takes place when an urban activity stops working (temporarily too).

Taking into account the several activities present in a city, the continuous changes it undergoes and the relationships that define the interaction, it is easy to understand the difficulty in defining procedures capable of regulating systemic evolution.

In order to implement a process for regulating this (spontaneous) evolution it is first necessary to investigate the parts and structure (set of relationships) of the system, trying to grasp the rules that cause the evolution and shift.

The subsequent step consists in identifying the policies (strategies) that, by establishing a set of achievable targets in specific time segments, can allow to the system to be controlled and steered towards future states included in a given range of optimal configurations, identified as the "desired state" (Figure 2).

Implementation of the strategies to meet the targets occurs in the third phase of the process. In any case it should be underlined that the system cannot remain inside the expected evolution range and, also due to misguided strategic definition or inadequate implementation of an action, could change by shifting to spaces that cause an entropic condition. Entropy has to be considered as a widespread negative condition of the system, which hinders the processes to achieve sustainability and tends to move the system towards the zone of entropy leading it and to follow trajectories totally different from those expected from its trend.

A clear example of the entropic condition is energy dissipation that should not be considered only as the poor use of resources but, for instance, as the waste of food strictly connected with the production of municipal waste. There are different segments inside the total amount. The first segment can be detected in 


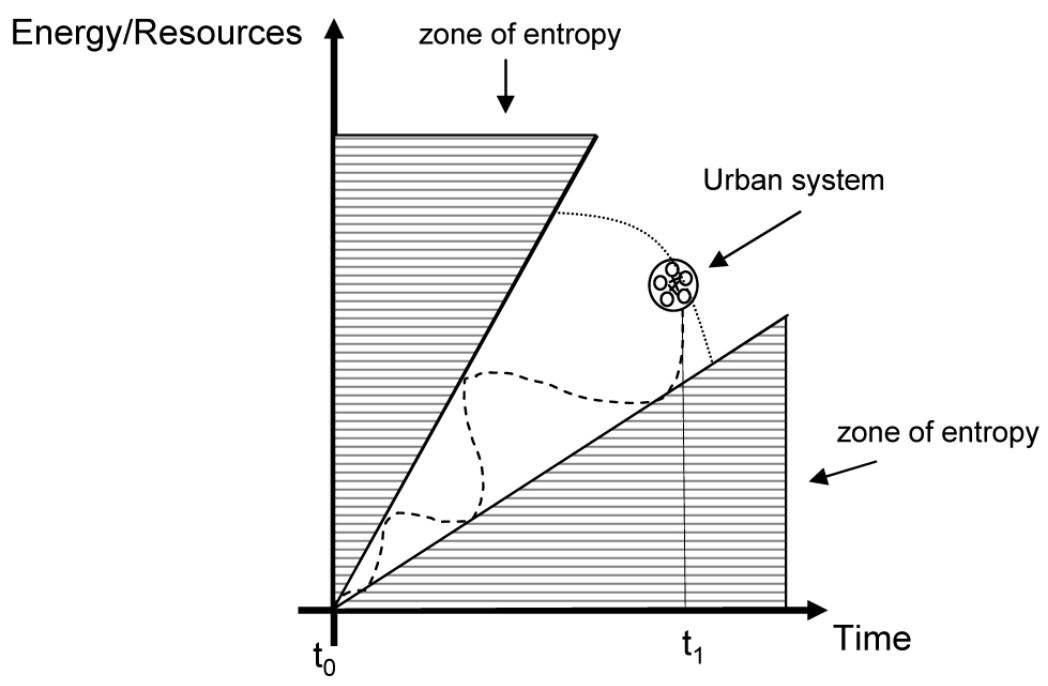

Figure 2: The evolution trend of the urban system In the conceptual pattern it is stressed the trend of the space-time evolution of the urban system that have to be hold back, by means of the process of territorial transformations within the angular range of the expected trajectories. (Axis of resources, range of expected trajectories, axis of time, arc of the possible system states at time $t_{1}$.)

the waste of crop food resources. In Italy in 2009 (according to ISTAT data) 17.7 million tons of crop production remained uncultivated, accounting for about $3.3 \%$ of overall production. The peaks refer to vegetables (12.5), legumes and potatoes (5.2). The reasons of this dissipation are unbelievably ascribable also to the shape and/or look of the products or more directly to the picking costs being higher than the market costs. The amount of fruit and vegetables wasted in 2009 could have met the needs of a nation similar to Italy.

Market reasons also determine the behaviour of farmers and producers cooperatives. Suffice it to say that in one year 73,000 tons of products are withdrawn from the market to avoid the fall of prices, only $4 \%$ of which is not wasted. A further paradox is the fact that the EU finances the purchase and the destruction of such products.

At the same time, the farmers are given funds to stay in the country and produce and contemporaneously to destroy part of the crops. Waste can be found also within the food industry chain which throws away two million tons of products each year. All that dissipated material becomes entropy i.e. waste, which implies a further cost for its disposal, without considering the harmful effects on landfills or incineration systems. Besides, we have to take into account the waste referable to the great distribution or to market activity, valued at $1 \%$ (always for market reasons). 
We can often observe, after the closing of supermarkets, the transport of large quantities of food eliminated also because it is necessary to continuously restock the shelves, in order not to make the consumer feel that there is a supply shortfall. Finally, considering the last segment, the one referring to consumers, it can be said that in school lunch waste reaches $13-16 \%$, in households $17 \%$ as regards fruit and vegetables and $39 \%$ as regards milk, eggs, meat, cheese. The causes are the same: purchase surplus and damage/alteration of the product for being kept too long in the pantry. There are many other examples of entropic dissipation within urban contexts, where at present a high percentage of the population lives, but those concerning food seem most appropriate to show that also the rules of the market economy drawn up and implemented by the wealthy West are leading to unsustainable levels, almost reaching crisis point, where there will be total devastation of the structure, a bifurcation that must be recognized and averted through the systemic approach.

\section{An in-depth study of the systemic logic as a reference for eco-town planning}

It can be assumed that a city is much more sustainable when physical and functional systems develop at a "compatible" speed, in other words, the urban system maintains a sustainable dimension when it keeps the activities inside the historic spaces of allocation. The farther the activities are kept from their traditional settlement sites - which greatly contribute to the perception and memory of the city - the more urban sustainability declines. In the works by Thomas More, at the end of the $16^{\text {th }}$ century, definitions related to the concept of food self-production were still in nuce, “... in the city all people produced their food ....", today suggested again by many economists to counter the present liberalistic economic model [8]. Even now, food and its production at urban sites is a good example to show the discrepancy between the physical system and the functional system [9].

The main adversary of sustainability inside the city is anthropogenic entropy. In order to start suitable processes to steer the urban system towards sustainable structures, it is necessary to reduce urban entropy. In anthropogenic entropy it is possible to distinguish direct action, which is represented by soil use in terms of location, extent and duration, and induced entropy consisting in emissions affecting the air and water quality air, as well as generating electromagnetic and noise pollution. Local firms need energy to carry out their functional cycle and the source of such energy is still fossil fuels (the phenomenon of the Canadian "tar sands" is a case in point).

Starting from the Prigogine's assumption that considers the city as a selforganized [10] complex ecosystem, it may be stated, also taking Muller's recent definitions [11] into account, that complexity is a factor that ensures the selforganization of environmental systems. The city is a dissipative structure that absorbs energy and gives off entropy. Within the ecosystem entropy exceeding a given threshold can no longer be metabolized by the system and has an impact 
on it by reducing its complexity, and through the decrease in the interrelations among the parts hinders its self-organizational capability.

We can assume that entropy reduces the energy required for relationships among the parts, succeeding in completely hindering them; accordingly, the system loses its self-organizing capability and inside it processes of "entropic atrophization" get started. The parts, being no longer distinguished and separated by the system structure (set of relationships), tend to coagulate into entropic clusters (ECs), which, inside the system, behave similarly to black holes in astrophysics.

ECs tend to re-establish their systemic structure, for which they require energy to reactivate interactions. Therefore the ECs try to absorb energy from other systems, annulling some relationships linking the elements. Thus the parts become isolated and are incorporated by the bunches, which increase their entropic mass and, consequently, require more relational energy. As the bunches increase (joining together) the system loses complexity and moves towards a hardening process that increasingly inhibits its possibility of control (Figure 3 ).
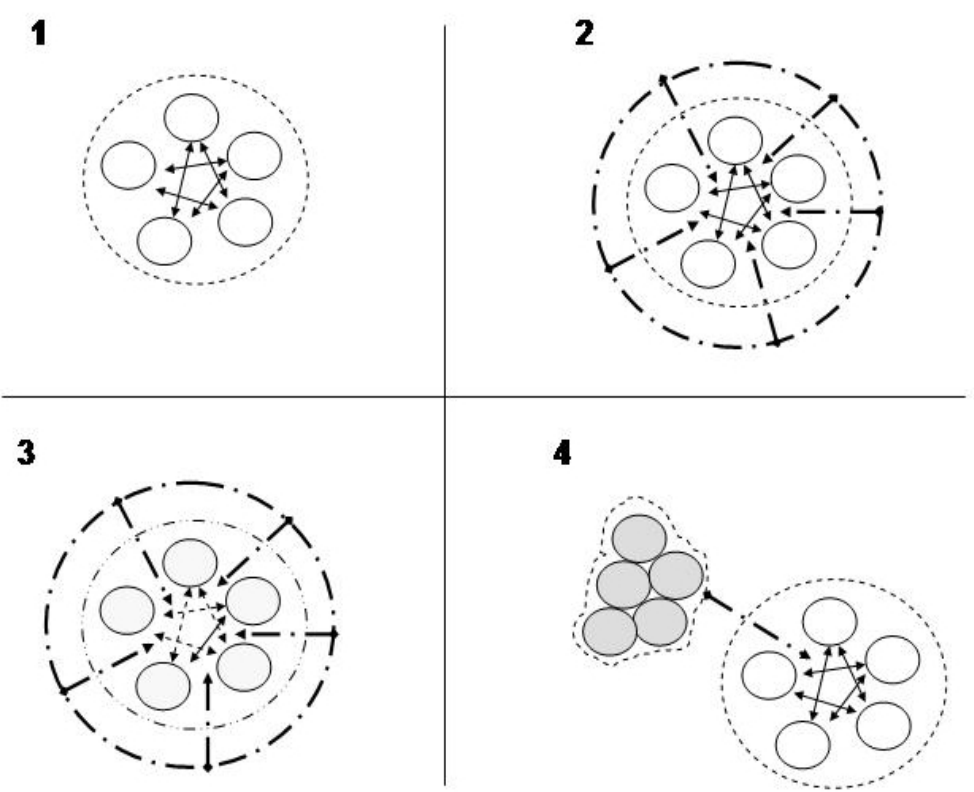

Figure 3: The stages of formation of entropic clusters. First, the system has elements and balanced relations (1), then entropy attacks the system structure (relationship) (2) and progressively degrades the interactions between the elements (3). Finally the system loses its structure and aggregates into clusters that act as parasites of other systems (4), trying to absorb energy relations, and added to if additional shares are no longer interacting. 
When the system exceeds a given level, the "resilience threshold" shows a considerable impoverishment of the structure, which has lost the quantity and quality of relationships that assure its evolution and self-organization. In this condition, the only relationships left to the decomplexified system are the exogenous ones; by acting on them at metasystemic level it is possible to inject new energy into the system in order to reactivate the endogenous structure.

Taking the above theories into account, can we assume that the ECs behave like antimatter? Can a subsystem in crisis change into an "anti-system"?

In order to answer those questions and develop the formulated hypotheses, we must first investigate the concept of complexity referring to the definitions made by the scientists such as Prigogine, Wilson, Rabino, etc. Moreover, also the concept of "self-organizing ecosystem" described by Tiezzi, Muller, etc. has to be analysed. Finally, the theoretical assumptions should be linked to the managing of territorial transformations and the entropy theory

Summing up, we can say that the ECs represent entropy clusters that decomplexify the urban system. In other words, a process of system "destructuring" is involved because the formation of ECs requires the removal of energy from the set of relationships that allow the system itself to survive.

The clusters can be considered an accumulation of waste (dyscrasia, poor use of resources, etc.) in urban metabolic processes (physical, functional, administrative, etc.) which remain in the system absorbing energy/resources. The system energy from the available resources should be considered the drivingforce of the different generative subsystems: physical, functional, social, geomorphological, psycho-perceptive. It may be possible to make some examples by imaging the ECs inside the cities and connecting them to each subsystem:

- $\quad$ physical: dumping grounds

- functional : disused areas

- social: reduction and loss of "social capital"

- geomorphological: natural risk-prone areas (hydrogeological instability, earthquakes, etc.) and anthropogenic risk-prone areas (soil, air, water, ether pollution, etc.);

- $\quad$ psycho-perceptive: loss of decorum and memory of places.

In conclusion we can state that ECs are similar to black holes which absorb resources and energy, producing entropic phenomena (from pollution to social conflict) throughout the urban subsystem, which consequently tend to collapse.

Starting from the above-stated hypotheses, it can be seen that on starting processes of managing territorial transformation leading the system to positive and sustainable structures, the first step is to identify the developing ECs or those already present inside the urban system and try to remove them immediately, or to activate their "relational revitalization", by implementing suitable policies and actions to deal with them. 


\section{Conclusions}

Our overall aim in this paper was to indicate a sound route towards urban sustainability that can lead citizens worldwide, of different ethnic groups, and dissimilar traditions and cultures, towards a joint perspective of urban sustainability, which would include local peculiarities, a functional mix and biogenetic "diversity" into urban governance priorities. Our planet is turning increasingly into an "urban planet" within which cities are increasingly the sites where people concentrate, many of whom lived just a few years ago in rural areas.

Cities cover only $2 \%$ of the whole earth but use about $80 \%$ of world energy and release about $80 \%$ of total $\mathrm{CO}_{2}$. It is within cities that the energy, food and water challenge should be faced and it is precisely within cities that the ethic reversal should be catalysed. The world population keeps on increasing and it will shortly be necessary to produce much more food and water in comparison to quantities available at present, albeit very unevenly distributed. It is estimated that there are about one billion obese people worldwide against one billion people without food.

The fossil sources are running out and cannot be considered the reference point in this perspective of world economic reorganization, if we consider that 10 calories of fossil energy are required to produce only one calorie of food energy.

Such assumptions are far from new: the author advanced them for the first time about 10 years ago. Now there is not much time left for scientific theorizing or analysis of the on-going phenomena; the evolution of urban systems has to be promptly controlled in order to address them towards frameworks based on sustainability.

In the present situation, real sustainability may be impossible to achieve, but there is a need for a new ethic based on the widespread knowledge of the precariousness of the present organizations. Eco-town planning may represent one of the possible ways to concretely organize cities by implementing actions to hinder, and if possible stop, the processes of anthropogenic entropy.

The first step in such processes should be to become aware that it is necessary to totally change our way of acting and interacting with the environment and with all the biologic components of the planet we live in.

\section{References}

[1] Fistola, R., Ecourbanistica: toward a new sustainable town planning, in: Brebbia C., Hernandez S., Tiezzi E., (eds.), The Sustainable City VI. Urban regeneration and sustainability, WIT Transactions on Ecology and the Environment, Series Volume: 129. WIT Press 2010.

[2] Fistola, R., La città come sistema, (Volume II, Chapter 2). Per il XXI secolo una enciclopedia. Città cablata e nuova architettura, eds. C. Beguinot and U. Cardarelli, Università degli Studi di Napoli "Federico II" (Di.Pi.S.T.), Consiglio Nazionale delle Ricerche (I.Pi.Ge.T.), Napoli, 1992. 
[3] von Bertalanffy, L., General System Theory, Penguin Books, Harmondsworth, 1972.

[4] Pulselli, R.M., Tiezzi, E., Città fuori dal caos. La sostenibilità dei sistemi urbani, Donzelli Editore, Firenze 2008.

[5] Fistola, R., M.E-tropolis- funzioni innovazioni trasformazioni della città, I.Pi.G.E.T. CNR - Giannini, Napoli 2001.

[6] Lynch, K, The image of the city, MIT Press, 1992.

[7] Rifkin, J., Entropy: Into the Greenhouse World, (with Howard, T.), Bantam Books, 1989.

[8] More, T., Utopia, Cassel \& Co.,1901, www.forgottenbooks.org

[9] Steel, C., Hungry City. How food shapes our lives, Random House, UK, 2009.

[10] Prigogine, I. \& Stengers, I., La Nouvelle Alliance, Gallimard, Paris, 1979.

[11] Müller, F., Thermodynamic constraints of ecosystem and landscape dynamics, Prigogine Medal Award Dissertation, La Coruňa, 2010. 